\title{
Zwiastun książkowy
}

- przeniesiony z kinematografii na grunt życia literackiego krótki film promujący książkę. Złożony jest z dynamicznie zmontowanych obrazów, informacji o autorze i samej książce, a często opatrzony także sloganami reklamowymi ${ }^{1}$. W odróżnieniu od zwiastuna filmowego nie jest prezentowany na ekranach kin, a jedynie w Internecie. Zwiastun książkowy utracił wiele synonimicznych określeń, charakterystycznych dla filmowego pierwowzoru, takich jak pochodzący z języka niemieckiego forszpan czy angielskie fore-runner, preview, comming attraction lub francuskie avant-coureur, pozostawiając ciągle rozpoznawalne formuły trailera książkowego i książkowej zajawki.

\section{Na początku był film}

Nie sposób mówić o zwiastunie książkowym, nie uwzględniwszy jego filmowej genezy. Powstały w Stanach Zjednoczonych we wczesnym okresie kina niemego jako skuteczny sposób dotarcia do jak największej liczby odbiorców, początkowo prezentowany był w formie statycznych slajdów zawierających wizerunki aktorów, wybrane sceny oraz eksponując tytuł filmu. Pierwotnie zwiastuny wyświetlane były po projekcji, oddzielając w ten sposób następujące po sobie seanse. Za moment narodzin trailera filmowego uznaje się rok 1912 oraz prezentację na Rye Beach koło Nowego Jorku kolejnego odcinka serii The Adventures of Kathlyn, zakończonego krótkim fragmentem z następnego filmu, mającym zachęcić do dalszego śledzenia przygód bohaterki²

Na kształt zwiastuna filmowego wpłynął dynamiczny rozwój przemysłu kinematograficznego. Powstające trailery stały się terenem coraz bardziej świadomego wykorzystywania technik reklamowych, większej kreatywności i bardziej wyszukanego stylu. Coraz częściej podkreślano rangę promowanego dzieła, odwoływano się do nazwisk uznanych twórców, nagród zdobytych przez reklamowany film oraz pozytywnych cytatów z recenzji. Pierwsze trailery, będące początkowo zlepkiem scen i napisów, zaczęły przybierać formę znacznie bardziej wyrafinowaną. W latach trzydziestych poprawnie zbudowany zwiastun zawierał zbliżenia twarzy aktorów, elementy graficzne i dynamiczne sceny akcji. Wraz ze wzrostem budżetów hollywoodzkich produkcji, podstawowym budulcem zwiastunów przestawały być jedynie gotowe materiały filmu lub fragmenty, z których z różnych powodów rezygnowano podczas montażu, a stawały się także specjalnie kręcone pod okiem reżysera materiały ${ }^{3}$.

\section{Sztuka reklamy}

Zwiastun to jeden najważniejszych elementów strategii marketingowej, a jego produkcji towarzyszy cel czysto utylitarny. Jest nim oczywiście przyciągnięcie uwagi oraz przekonanie, że reklamowany film jest właśnie tym, który widz powinien zobaczyć. Jadwiga Mostowska zauważa, że konstrukcja zwiastuna podporządkowana bywa raczej wywołaniu określonych emocji niż zachowaniu spójnej, przejrzystej narracji ${ }^{4}$. Lisa Kernan, autorka książki Coming Attraction. Reading

1 Definicja zaczerpnięta z artykułu Zwiastun filmowy, [w:] Encyklopedia kina, red. T. Lubelski, Kraków 2003.

${ }^{2}$ Zob. J. Mostowska, Zwiastun: fragment historii kina, jeden z gatunków filmowych, element kultury filmowej, „Kwartalnik Filmowy” 2007, nr 57-58, s. 182.

${ }^{3}$ Doskonałym przykładem takiego podejścia twórcy do materiału reklamowego był Alfred Hitchcock. Realizował je sam bądź nadzorował ich produkcję. Utrwaliło się wspomnienie Peggy Robertson, wieloletniej asystentki reżysera: „Każdy film Hitchcocka to był w 99,9 proc. Hitchcock. To był zawsze Hitch i z trailerami było podobnie”. Cyt. za: M. Sadowski, Trailery, zwiastuny, forszpany - historia i rozwój, <http://www.audiowizualni.pl/ index.php/promocja-filmu/reklama/7085-trailery-zwiastuny-forszpany-historia-i-rozwoj> [dostęp: 3.06.2016].

${ }^{4}$ Zob. J. Mostowska, Zwiastun..., s. 183-184. 
American Movie $^{5}$, analizując 27 amerykańskich zwiastunów filmowych, identyfikuje w nich trzy główne strategie retoryczne, które rządzą ich strukturą. Są nimi odwoływanie się do zainteresowania publiczności gatunkami filmowymi, opowiadaną historią i gwiazdami. Nie dziwi więc fakt, że jedną z ważniejszych strategii jest eksponowanie wizerunku oraz dokonań aktorów, którzy w filmie występują. W dobie Internetu zwiastun spełnia jeszcze jedną funkcję: zapewnia publiczności możliwość udziału w rzeczywistości związanej z filmem także poza kinem i buduje przywiązanie do głównych bohaterów, tworząc i jednocześnie zaspokajając odbiorcze potrzeby ${ }^{6}$.

Nie należy wszakże zapominać o tym, że trailer to forma z pogranicza kina i reklamy. Nie jest oczywiście zjawiskiem samodzielnym, lecz powstaje jako element wtórny podczas pracy nad filmem. Nie przeszkadza to jednak, by zwiastun traktować coraz częściej jako krótką formę filmową czy wręcz odrębny gatunek filmowy. Na taką opinię wpływa jego skonwencjonalizowana struktura, w której nacisk kładziony jest albo na linearność opowieści, zamykanej przez twórcę niedopowiedzeniem, albo na zaprezentowanie widowiskowych ujęć, powstałych z użyciem efektów specjalnych. Produkcją trailerów nie rządzi oryginalność, lecz funkcjonalność. Błyskawiczny i natężony odbiór w krótkim czasie wymaga powtarzalnej kombinacji czynników. Obecność zwiastuna w kulturze popularnej nie ogranicza się jedynie do jego oglądania i funkcji kolejnej formy rozrywki. Świadczą o tym rozmaite trawestacje, którym jest poddawany. Przykładem mogą być tzw. fake trailers, a więc zapowiedzi nieistniejących filmów, odwołujące się zazwyczaj do stricte gatunkowego myślenia o kinie oraz fanowskie, parodystyczne wersje popularnych zajawek, zwane spoofs ${ }^{7}$. Trailery stają się również przedmiotem szczegółowych analiz, a także służą jako materiał porównawczy do badań socjologicznych oraz kulturoznawczych ${ }^{8}$.

\section{Trailer czyli przyczepa. Problemy z literaturą}

Według Piotra Kowalczyka zwiastun książkowy jest obok e-booka, audiobooka czy fragmentu książki na blogu przykładem książki 2.0, a więc występującej w każdej nowocześniejszej niż papierowa postaci ${ }^{9}$. Trailer ściśle związany jest z przestrzenią Internetu. Zupełnie nie występuje poza sferą WWW (np. jako dodatek do książki, vide: zwiastun filmowy umieszczany na kasecie VHS i płycie DVD), ale przede wszystkim funduje swoje istnienie na medium internetowym, dzięki czemu spełnia warunek, jaki Piotr Marecki stawia „literaturze sieci” w ramach terminu liternet ${ }^{10}$.

${ }^{5}$ L. Kernan, Coming Attraction. Reading American Movie, Austin 2004.

${ }^{6}$ Więcej na temat marketingowych przykładów zbliżania do siebie bohaterów i odbiorców pisze Maja Strzelecka w tekście Tajemnice filmowych zajawek, <http://wyborcza.pl/1,75410,4719896.html> [dostęp: 3.06.2016]. Z kolei $o$ promocji filmów bazującej na dawkowaniu napięcia za pomocą zwiastunów pisze Rafał Kulczyk, Sztuka ekstraktu, <http://kultura.newsweek.pl/sztuka-ekstraktu,29286,1,1.html> [dostęp: 3.06.2016].

${ }^{7}$ Zob. M. Walkiewicz, Tajniki filmowej gry wstępnej, <http://film.onet.pl/wiadomosci/tajniki-filmowej-grywstepnej/8h6c4> [dostęp: 3.06.2016].

${ }^{8}$ Zob. J. Mostowska, Zwiastun..., s. 181.

${ }^{9}$ P. Kowalczyk, W stronę książki 2.0, <https://pl.scribd.com/doc/16628606/W-stron\%C4\%99-ksi\%C4\%85\%C5\%BCki2-0-prezentacja-na-Bookcamp-09-1> [dostęp: 3.06.2016].

${ }^{10}$ Liternet. Literatura i internet, red. P. Marecki, Kraków 2002, s. 7. Warto odnotować, że pierwsze próby tworzenia reklam książek są nieco wcześniejsze, czego przykładem może być telewizyjne nagranie promujące książkę Johna Farrisa, pt. Wildwood pochodzące z 1986 roku. Popularność zwiastuna książkowego związana jest jednak stricte z możliwościami internetowymi i sięga ostatnich kilkunastu lat oraz takich aktywności sieciowych, jak blogosfera, portale wydawnicze i ksiażkowe czy wreszcie powstaty w 2014 roku serwis BookReels, umożliwiajacy wydawcom i autorom udostępnianie dowolnych multimedialnych treści poświęconych książkom. 
Według Niny Metz zwiastun książkowy jest formułą nieoczywistą ${ }^{11}$. W rzeczywistości, w której coraz więcej czytelników polega na Internecie jako głównym źródle informacji na temat literatury, czytając recenzje, kupując książki lub wyszukując wywiady z autorami, trailer powinien z łatwością wpisać się w to równanie. Nie dzieje się tak zdaniem autorki z kilku powodów. Pierwszym jest wykonanie, zwiastuny książkowe tworzone są bowiem niskim kosztem, często w domowym zaciszu ${ }^{12}$. To, co otrzymują czytelnicy, to zazwyczaj dosłowna reprezentacja. Forma jest co prawda zbliżona do zwiastuna filmowego, $\mathrm{z}$ aktorami odgrywającymi sceny pochodzące $\mathrm{z}$ książki, animacją lub zwykłą serią zdjęć wyświetlanych z podkładem muzycznym oraz tekstem przekazującym opowieść, ale zazwyczaj jest to wideo $\mathrm{z}$ udziałem nieznanych aktorów poprzebieranych za postaci z książki, kreskówki albo charakterystyczne przede wszystkim dla wczesnych trailerów - zmieniające się zdjęcia książki oraz autora.

Trudność odbioru zwiastuna, który nie jest ani wywiadem z autorem, ani nagraniem składającym się z rozczłonkowanych materiałów filmowych, w którym twórca opowiada o swoim pisarstwie, ani też wideorecenzją dostępną na stronie internetowej, blogu lub vlogu, zasadza się na mechanicznym powieleniu metody propagującej sztukę filmową, a więc braku uwzględnienia specyfiki literatury. Trailer z natury rzeczy poprzedza pierwszy kontakt z książką i stoi w sprzeczności z obrazotwórczym charakterem wyobraźni. Akt czytania jest działaniem prywatnym, a jakakolwiek wcześniejsza wizualna prezentacja książki nosi znamiona powszechności ${ }^{13}$. Drugą trudnością jest zatem automatyzacja, która w przypadku zwiastuna filmowego sprawdza się, jest przecież powieleniem przedstawianego w filmie obrazu, kopią jego fragmentów, ale na gruncie literatury staje się kreacją, czyli pierwszym odczytaniem, częściową adaptacją lub nawet interpretacjąa ${ }^{14}$.

${ }^{11} \mathrm{~N}$. Metz, Super sad book trailers. The conundrum of online book advertisements - and why they usually fail, "Chicago Tribune" 6.06.2012, <http://articles.chicagotribune.com/2012-07-06/features/ct-prj-0708-booktrailers-20120706_1_book-trailers-publishers-videos> [dostęp: 3.06.2016].

${ }^{12}$ Osobnym zagadnieniem są poradniki poświęcone samodzielnemu wydaniu książek, w których temat tworzenia zwiastuna książkowego urasta do miana odrębnej aktywności artystycznej, zob. S.C. English, The Book Trailer ${ }^{\circledR}$ Revolution, 2008, <http://www.cosproductions.com/pdf/BookTrailerRevolution_DigitalVideoMarketing.pdf>[dostęp: 3.06.2016]; J. Deveal, Publicize Your Book (Updated): An Insider's Guide to Getting Your Book the Attention It Deseres, New York 2008; M. Raymond, Everyday Book Marketing: Promotion Ideas to Fit Your Regularly Scheduled Life, Ashland 2013.

${ }^{13}$ Nina Metz cytuje Petera Mendelsunda, twórcę książkowych obwolut: „In a way, that's the key to jacketing books: You have to respond to what the key themes of the book are, what the author's project is, but you cannot give too much away. You have to respect the fact that people's imaginations are deeply private".

${ }^{14}$ Warto przyjrzeć się próbom sklasyfikowania rodzajów zwiastuna książkowego. Autorką jednej z takich typologii jest gospodyni bloga Pierogi Pruskie. Wykorzystując specyfikę internetowego diariusza, łączy krytyczne omówienie z humorystycznym nazewnictwem. Wyróżnia następujące rodzaje trailerów książkowych: „taki ze mnie prawdziwy zwiastun, ho, ho" - cechuje się on szybkim montażem zmieniających się ilustracji, obecnością lektora i informacją o premierze, tworzy mu pewne wyobrażenie o książce, bardzo zbliżone do filmu; „chcecie? No to macie” filmowa adaptacja sceny bądź kilku scen pochodzących z reklamowanej książki, charakteryzuje się powolnym montażem i długimi ujęciami poszczególnych scen, a czasem również obecnością książkowego narratora, który opuścił świat przedstawiony, by przybliżyć go odbiorcy; „przeczytam ci okładkę” - trailer przyjmujący formę prezentacji multimedialnej z udziałem tekstu i grafiki komputerowej bazuje głównie na przedstawieniu okładki; "reklamuję książkę, ale chciałbym film” - zwiastun zbliżony do swojego kinowego pierwowzoru, wykorzystujący szereg zabiegów filmowych do unaocznienia świata przedstawionego, w czym wyręcza czytelniczą wyobraźnię, ten rodzaj kompromituje bezpośrednie przełożenie rzeczywistości literackiej na filmową, nie uwzględniając odmienności obu procesów twórczych; „po co wiedza, o czym jest książka, lepiej posłuchaj, jakie przymiotniki do niej pasują!" -zbudowany z następujących po sobie ujęć haseł, mających oddać warstwę emocjonalną książki (np. „nienawiść, agresja, frustracja, pożądanie” w zwiastunie Gniewu Zygmunta Miłoszewskiego) oraz wykorzystujący gatunkowe skojarzenia; „zachęcę cię, ale nie będę udawał - jestem zwiastunem książki i mam ograniczony budżet” - oparty na koncepcie i wykorzystujący specyfikę literatury trailer zbliża się formalnie do gawędy, starający się uchwycić podstawowy problem książki; „, końcu chodzi o ruchome obrazki, nie?” - zdradza dużą część fabuły i wykorzystuje klisze filmowe, ponownie zbliżając trailer książkowy do zwiastuna filmowego; „w końcu książka to inne medium" - uwzględnia tekstowy charakter literatury i podobny do literal music video (trawestacji oficjalnego wideoklipu, który tworzą następujące po sobie ujęcia kolejnych wersów tekstu); „trochę jestem zwiastunem, trochę jestem recenzją" - zwiastun zbliżający się do video blurb (nagranie wykorzystujące pozytywne opinie, umieszczane najczęściej na pierwszej i czwartej stronie okładki), koncentrujący się na recepcji, a nie samej książce. Zob. <http:// pierogipruskie.blogspot.com/2015/03/o-zwiastunach-ksiazek-albo-o-problemach.html> [dostęp: 3.06.2016]. 
Ostatnią przeszkodą jest nazwa. Zwiastun, trailer, zajawka - wszystkie te terminy w pierwszej kolejności konotują przemysł kinematograficzny, a nie wydawniczy oraz oferują wiele doskonale znanych strategii i oczekiwań, które sprawdzają się w przypadku filmu, ale nie wobec książek. Taka promocja jest więc czymś wtórnym i narzuca literaturze zewnętrzny, obcy jej porządek. Otwarte pozostaje pytanie o to, jak wzbogacić doświadczenie czytelnicze metodami wizualnymi, nie redukując książki do jej warstwy narracyjnej i stworzyć immanentną formę reklamy, wykorzystującą nowe media ${ }^{15}$. Nieśmiałą odpowiedzią może być „video blurb” - charakterystyczna dla literatury forma rekomendująca książkę, przeniesiona z okładki do krótkiego filmu promocyjnego, w którym znane osobistości mówią z pasją o książce i własnym czytelniczym doświadczeniu.

Zwiastun książkowy jest jednym z możliwych sposobów promowania literatury w nowomedialnym środowisku, wykorzystującym metody komputerowe. Autorzy trailerów książkowych niezmiennie stoją przed wyzwaniem, w jaki sposób przedstawić kilkustronicowy tom złożonych opisów i charakteryzacji oraz przeplatających się wątków w kilkudziesięciosekundowym filmie. Za największą trudność w konceptualizacji zagadnienia należy uznać zależność od zwiastuna filmowego oraz konkurencyjność odmiennych wizualnych form przedstawiania literatury.

\section{Cezary Rosiński}

\footnotetext{
${ }^{15}$ Metz sugeruje, że w pierwszej kolejności powinna zostać zaproponowana nowa nazwa dla opisywanego zjawiska, która oddawać będzie jej literacką odrębność. W artykule jako propozycja pojawia się termin „bideo”. Zob. N. Metz, Super sad book trailers...
} 


\title{
SŁOWA KLUCZOWE:
}

\author{
zwiastun książkowy
}

NOWE MEDIA

\section{AbSTRAKT:}

Hasło prezentuje w kontekście poetyki oraz kinematografii nową formę promocji literatury, jaką jest zwiastun książkowy. 


\section{zwiastun filmowy \\ reklama}

NOTA O AUTORZE:

Cezary Rosiński - doktorant na Wydziale Filologii Polskiej i Klasycznej Uniwersytetu im. Adama Mickiewicza w Poznaniu. Do jego zainteresowań badawczych należy najnowsza proza polska, zagadnienie starości i przestrzeni w literaturze. Jako krytyk literacki współpracuje z „Nowymi Książkami” i „Odrą”. Niedawno ukłzała się jego książka „Ocalić starość. Literackie obrazy starości w polskiej literaturze najnowszej”. 